\title{
Understanding pelvic floor in women
}

\author{
Rajni Mittal $^{1 *}$, Gayatri Rath ${ }^{2}$, R. N. Sahai ${ }^{3}$, Mahima Aggarwal ${ }^{1}$
}

\begin{abstract}
${ }^{1}$ Department of Obstetrics and Gynecology, NDMC Medical College and Hindu Rao Hospital, Delhi, India
${ }^{2}$ Department of Anatomy, NDMC Medical College and Hindu Rao Hospital, Delhi, India

${ }^{3}$ Department of Surgery, NDMC Medical College and Hindu Rao Hospital, Delhi, India
\end{abstract}

Received: 30 July 2020

Accepted: 05 September 2020

\author{
*Correspondence: \\ Dr. Rajni Mittal, \\ E-mail: rajnimttl@yahoo.com
}

Copyright: (C) the author(s), publisher and licensee Medip Academy. This is an open-access article distributed under the terms of the Creative Commons Attribution Non-Commercial License, which permits unrestricted non-commercial use, distribution, and reproduction in any medium, provided the original work is properly cited.

\begin{abstract}
Change from quadruped to erect posture has resulted in changes in the human pelvis. This has resulted in pelvis supporting the abdominal viscera. The bony pelvis is deficient on inferior aspect. Muscles covered by fascia on superior and inferior aspect. A good knowledge of pelvic floor is very basic and mandatory for any gynecologist as pelvic floor is crucial to support the pelvic organs and is required to maintain urinary and fecal continence.
\end{abstract}

Keywords: Pelvic floor, Levator ani, Perineal membrane

\section{INTRODUCTION}

The female pelvic floor has not been studied much from biomechanical aspect. Muscles of pelvic floor have two major functions in women firstly they provide support for pelvic organs or act as a "women, firstly" for the abdominal viscera and secondly it provides continence mechanism to the various orifices including urethral, anal and vaginal orifices. ${ }^{1}$ Pelvic floor supports the uterus just like a ship in water anchored by ropes where ropes are the ligaments, water is the muscular support and ship is the uterus. If the water levels fall enough then ropes will ultimately break and ship will fall down. ${ }^{2}$

In women, pelvic floor allows urination and defecation when desired but prevents incontinence of urine and feces and pelvic organ prolapse whenever intra-abdominal pressure is raised. Unlike the males, pelvic floor must also allow childbirth in women. ${ }^{1}$ Pelvic floor dysfunction may lead to pelvic organ prolapse and incontinence of urine and bowels later in life. These require complex surgeries with almost $1 / 3$ rd needing repeat surgery. ${ }^{3}$

A gynecologist routinely encounters the problems related to pelvic floor dysfunction in day to day life. So, understanding the anatomy and function of pelvic floor is very crucial.

\section{EVOLUTION OF FEMALE PELVIS AND ITS RELATIONSHIP TO PROLAPSE}

The transition from quadruped ambulation to modern bipedalism together with the loss of tail has brought about changes in the human pelvis. ${ }^{4}$

The first skeletal change for bipedalism was seen in fossils 4 million years ago when species had a partly arboreal life with some time being spent upright. Here the abdominal wall supported the abdominal viscera most of the time with the pelvis bearing the responsibility partially. ${ }^{5}$

As the primates started spending more and more time upright the changes in the pelvis became more pronounced becoming more sagittal oriented and shorter in the superior-inferior plane. The ilium became broader faced to support the upright posture while the sacrum became wider, broader and more tilted anteriorly. The pubis too inclined $45^{\circ}$ while standing as compared to near vertical in apes. There was increase in lumbosacral angle and the ischial spine moved anteriorly as the posture acquired 
uprightness. The pelvis too had to widen to accommodate a larger human head while the outlet had to remain small to prevent prolapse. The opening in the bony pelvis gradually shifted at the bottom of the abdominopelvic cavity. Hence there was a need of supportive system to prevent fall of pelvic organs through this defect. ${ }^{6}$ The supportive system evolved and now consists of a shelf like fibromuscular floor which spans the pelvic outlet but has a cleft for excretory drainage and birth canal. ${ }^{6}$

With upright posture the levator ani which was short and round in quadrupeds became long and thinned as motion of tail was done primarily by levator ani. With tail gone the pubococcygeus and iliococcygeus became shortened and broadened to occlude the pelvic outlet. ${ }^{7}$

The muscles and fascia in apes became more fibrous in humans to lend strong support without much tone. Hence the urogenital diaphragm developed which is derived from pubococcygeal fascia and provides support to the weakest area of the pelvic floor i.e. the point where vaginal, urethral and anal orifice lie. ${ }^{8}$

All these changes resulted in the birth canal which was straight and horizontal in early mammals to become curved in humans. Hence human childbirth now required various manoeuvres to succeed and this has made vaginal child birth difficult and increased the risk of prolapse.

\section{ANATOMY OF PELVIC FLOOR}

Pelvic floor is dome shaped fibromuscular shelf that separates the pelvic cavity from perineum for which it forms the roof. Pelvic floor consists of pelvic diaphragm, anteriorly in the midline, the perineal membrane and the muscles in the deep perineal pouch. Pelvic floor consists of all the structures which support the pelvic organs (Figure 1-3). ${ }^{9-11}$ Pelvic diaphragm lies within the lesser pelvis. It spans from one pelvic sidewall to the other and it contains a cleft for the birth canal and excretory drainage.

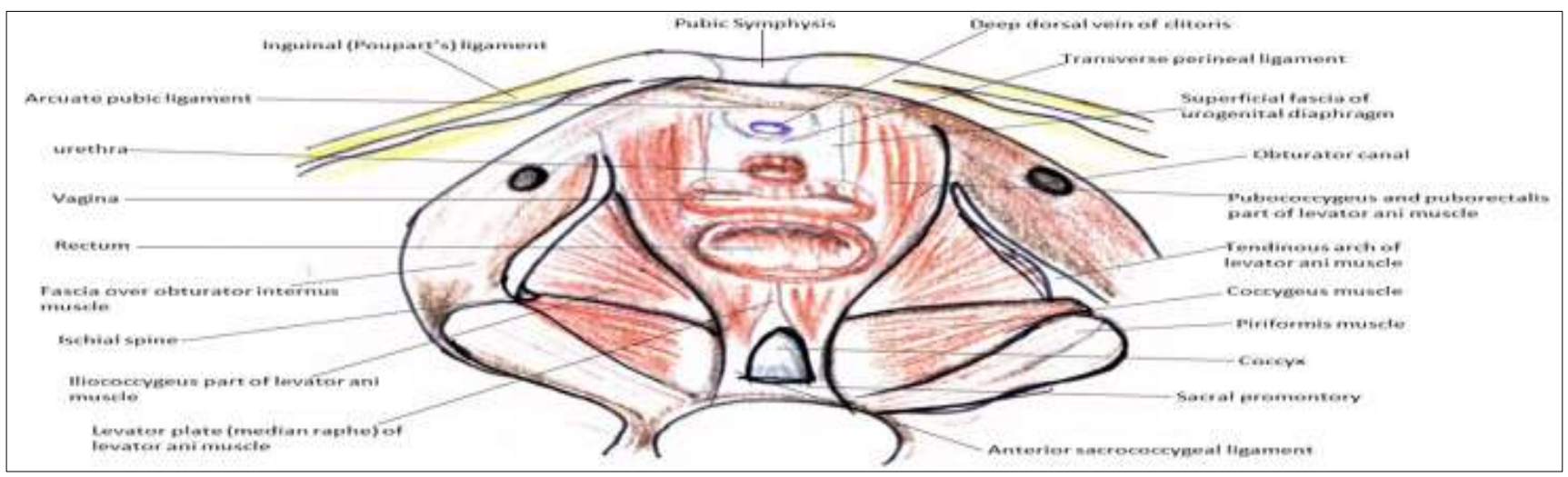

Figure 1: Pelvic floor (as seen from above).

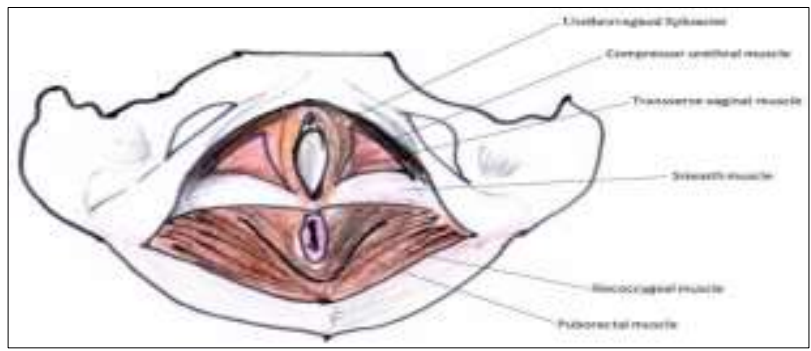

Figure 2: Pelvic floor as seen from below layer wise view.

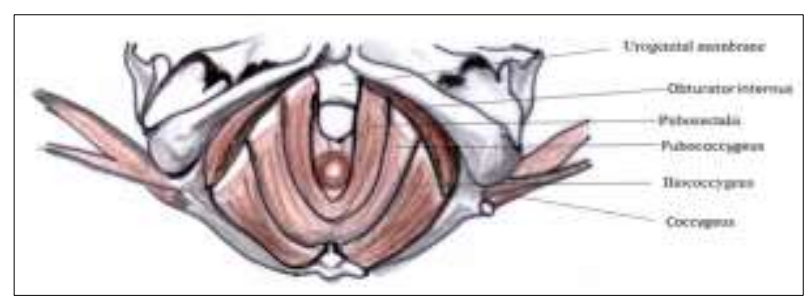

Figure 3: Pelvic floor as seen from below after removing the superficial layers.

\section{Pelvic diaphragm}

It is bowl or funnel shaped structure and forms the muscular floor of the pelvis. Pelvic diaphragm stretches between the anterior, lateral and posterior walls of the lesser pelvis, and appears like a hammock suspended from these attachments to close most of the ring of the pelvic girdle (Figure 1). ${ }^{11}$

Pelvic diaphragm consists of levator ani muscles, coccygeus muscle and the fascia (levator fascia) covering it on both superior and inferior aspect. ${ }^{6,10,11}$ Levator ani muscles from both the sides combine together and form the pelvic diaphragm. The circular line of attachment of pelvic diaphragm to the cylindrical pelvic wall lies between the greater and lesser sciatic foramen on each side (Figure 46 ). Thus, greater sciatic foramen is situated above the level of pelvic floor and is a route of communication between pelvic cavity and gluteal region of the lower limb; and lesser sciatic foramen is situated below the pelvic floor, providing a route of communication between the gluteal region of the lower limb and perineum. ${ }^{10}$ 


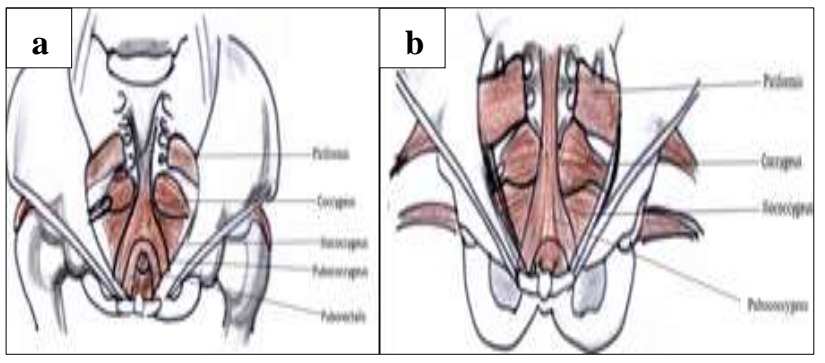

Figure 4: (a) and (b) Pelvic diaphragm as seen from above.

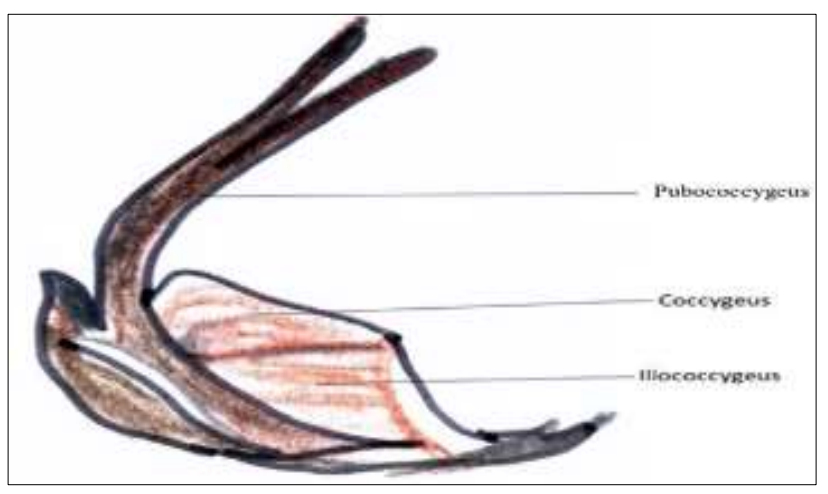

Figure 5: Lateral view of pelvic diaphragm.

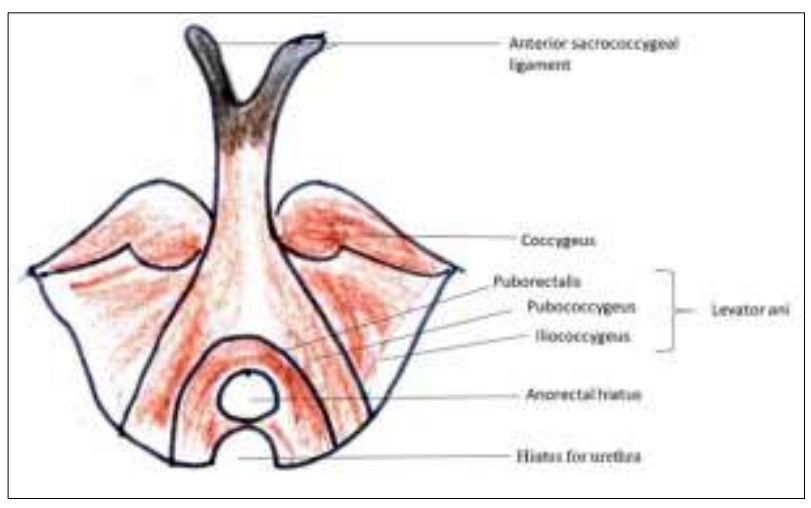

Figure 6: Pelvic diaphragm dissected free showing levator ani and coccygeus muscle.

\section{Levator ani muscle}

Levator ani is funnel shaped pair of striated muscles and is larger and more important part of pelvic diaphragm. It has slow-twitch fibres that maintain constant tone and fasttwitch (type II) fibres which have an increased density in the periurethral and perianal areas. ${ }^{6}$

Levator ani is covered by connective tissue on superior and inferior side by fascia called the superior and inferior fascia of the levator ani. The two levator ani muscles originate from each side of the pelvic wall, course medially and inferiorly, and join together in the midline. ${ }^{10}$

In the midline anteriorly levator ani muscle has a ' $U$ ' shaped defect called levator ani hiatus or urogenital hiatus which gives passage to the urethra, vagina and anus. Urogenital hiatus is supported anteriorly by pubic bones, the levator ani muscles laterally, and dorsally (posteriorly) by perineal body and external anal sphincter. This gap is covered on inferior side by perineal membrane. ${ }^{10}$

\section{Levator plate}

Medial fibers of the two sides merge together behind the anus to form a fibrous raphe or tendinous plate called levator plate which extends between anus and the coccyx. Behind anus, it forms anococcygeal ligament (anococcygeal body) which is a ligament or raphe and posteriorly attaches to coccyx. ${ }^{11}$ It is formed by the fusion of the iliococcygeus and the posterior fibres of the pubococcygeus muscles. It provides a shelf on which the pelvic organs like uterus, upper vagina and rectum rest. The levator plate is horizontal in standing position. ${ }^{6,12}$

\section{Attachments}

Levator ani is attached to posterior surface of pubis, fascia over obturator internus called arcus tendineus and ischial spine and inserts on coccyx and then meets in the midline on the midline raphe. Arcus tendineus is a fascial thickening on the surface of obturator internus muscle bilaterally on each side of urethra and vagina that runs from the pubic ramus ventrally to the ischial spine dorsally and gives origin to levator ani (Figure 1,3 and 4). ${ }^{13}$

Arcus tendineus fascia is well defined as a fibrous band near its origin at the pubic bone but becomes a broad aponeurotic structure as it passes dorsally to insert into the ischial spine.

Levator ani has three parts namely puborectalis, pubococcygeous and ileococcygeous (Figure 4-6). ${ }^{10,11}$

\section{Puborectalis muscle}

These are the thicker, narrower medial fibers of levator ani muscle. It originates from posterior aspects of the bodies of the right and left pubic bones. It is continuous between the two pubic bones as it passes inferiorly and fuses with its counterpart from the opposite side to form a ' $U$ ' shaped sling behind the ano-rectum and bounds the urogenital hiatus. It maintains an angle of 90 degree called perineal flexure between the anus and rectum and thereby plays an important role in maintenance of fecal continence. ${ }^{10,11}$

\section{Pubococcygeus}

These are the wider but thinner intermediate fibers of levator ani which lie lateral to puborectalis. Since majority of the attachments of pubococcygeous are to the vagina and anus, the term pubovisceral muscle is replacing this older term. It arises from inner surface of pubic bone and arcus tendineus, and passes posteriorly in almost horizontal plane. Medial fibers merge with fibers from opposite side to form levator plate and anococcygeal 
raphe. The small muscular slips of anterior fibers of pubococcygeous muscle extend medially to merge with the fascia of the midline structures, distal and lateral to vagina, perineal body, and anus. They loop around vagina in females (pubovaginalis) and anorectal portions and insert into perineal body and external anal sphincter muscle. The urethral portion forms part of the periuretheral musculature. ${ }^{14}$ Most lateral fibers attach to the superior surface of the coccyx; hence it is called pubococcygeus. . $^{6,10,11}$

\section{Ileococcygeus}

They are the thin posterolateral fibers of levator ani which are poorly developed and appears more aponeurotic. It spans between two pelvic side walls. It arises from posterior tendinous arc and ischial spine. Posteriorly the medial fibres blend with anococcygeal body to form Levator plate and lateral fibres attach to the last 2 segments of the coccyx..$^{6,10,11}$

\section{FUNCTION OF LEVATOR ANI}

Primary functions of levator ani are to support the abdominopelvic viscera, vagina and assist in maintaining urinary and fecal continence.

\section{Pelvic support}

The levator ani forms a dynamic floor. The resting tone of levator ani is similar to postural muscles of the spine. At rest, it is tonically contracted most of the time to support the abdominopelvic viscera, keeps the genital hiatus closed and maintains urinary and fecal continence. Pelvic floor carries the weight of the abdominal and pelvic organ. At rest, the normal tone of the muscles of the pelvic diaphragm keep the base of the U pressed against the backs of the pubic bones, keeping the vagina and rectum closed. ${ }^{6}$ If vagina has adequate depth, the upper vagina lies nearly horizontal in the standing female. During activities which raise intraabdominal pressure e.g. coughing, sneezing, forced expiration, vomiting, and lifting heavy objects, Levator ani contracts actively primarily to increase support of the pelvic viscera. This active contraction narrows the genital hiatus and compresses the upper vagina against the levator plate and thereby prevents pelvic organs prolapse (POP). This contraction of levator ani also contributes to increase the intraabdominal pressure to facilitate expulsion. ${ }^{11}$

\section{Protection of pelvic connective tissue}

Association between levator ani muscles and connective tissues is crucial for pelvic organ support. The resting tone of levator ani prevents undue stretching of these pelvic ligaments. The fasciae simply act to stabilize the organs in their position above the levator ani muscles. ${ }^{15}$ With tonically contracted levators, the connective tissues just stabilize these organs above the pelvic muscles. With damaged muscles, the entire weight of pelvic organs is born by connective tissue ligaments. They are capable of sustaining the weight for short term but ultimately they stretch and give way and lead to pelvic organ prolapse.

\section{Support of vagina}

The pubococcygeus muscle helps suspend the vaginal wall to the pelvis. Multiple connections between perineal body, pelvic side wall and levator ani prevent descent of posterior vaginal wall. Lower $1 / 3$ rd of posterior vaginal wall is supported by attachment of vagina to perineal body. Middle $1 / 3$ rd by attachment of vagina to levator ani by endopelvic fascia. The medial thickenings of these attachments are called rectal pillars. Upper $1 / 3$ rd of vagina is supported by cardinal ligament and vaginal portion of uterosacral ligament. Defects in the support at the level of the perineal body most frequently occur during vaginal delivery and are the most common type of posterior vaginal wall support problem. ${ }^{16}$

\section{Urinary continence}

Maximum contraction of pubovisceral muscles and the puborectalis muscles further compress the mid urethra, distal vagina, and rectum against the pubic bone distally and against abdominal hydrostatic pressure more proximally. ${ }^{17}$ There is a supportive hammock under the urethra and vesical neck. During periods of cough or increased intraabdominal pressure, levator ani muscle contracts simultaneously and the hammock provides a firm backstop against which the urethra is compressed. This maintains urethral closure pressures above the rapidly increasing bladder pressure and does not allow downward displacement of urethra and thereby prevents leakage of urine. ${ }^{18}$

\section{Anal continence}

Puborectalis loops around the funnel spout of anorectum to maintain the anorectal angle and prevents filling of anal canal at rest. This maintains fecal continence during rectal filling or peristalsis with full rectum and the involuntary sphincter muscle is relaxed. Voluntary squeezing of the puborectalis may increase the tone to counter increased intra-abdominal pressure. The levator ani muscle relaxes to allow defecation and micturition. During defecation or micturition, the intraabdominal pressure increases by contraction of muscles of anterior abdominal wall, thoracic diaphragm. The levator ani relaxes to descend the pelvic floor, angle between rectum and anus increases and feaces flows from rectum to anus. ${ }^{11,19}$

\section{Nerve supply of levator ani muscle}

Direct innervation of the levator ani muscle on its cranial surface is primarily from the anterior branch of third and fourth sacral nerve roots via the pudendal nerve, called appropriately the nerve to the levator ani. The puborectalis may derive some if its innervation on the caudal side from inferior hemorrhoidal branch of pudendal nerve. ${ }^{20,21}$ 


\section{Coccygeus}

Coccygeus muscle forms posterior part of the pelvic diaphragm. It arises from the lateral aspects of the inferior sacrum and coccyx. The fleshy fibers of coccygeus lie on the deep surface of the sacrospinous ligament and attach medially to ischial spines. It is innervated by branches of anterior rami of sacral spinal nerves- $\mathrm{S}_{2}, \mathrm{~S}_{3}$ and $\mathrm{S}_{4}$ (Figure $4-6)^{22}$

\section{Assessment of levator ani}

The levator ani muscle should be assessed for tone, tenderness, spasm and avulsion.

The levator tone is assessed by palpating vaginal wall at 5 and 7 o' clock position about $2-4 \mathrm{~cm}$ above hymen. The woman is asked to squeeze her vaginal muscles as though she is holding gas or stopping urine flow. By this procedure, we assess the tone of pubococcygeous and puborectalis muscles. Mid and dorsal iliococcygeus muscles are not circumvaginal so their maximal contraction elevates the central region of the posterior pelvic floor but contributes little to a vaginal measurement of Levator strength or pressure. ${ }^{1}$ The strength is graded from 0 to 5 using modified oxford scale 4 as follows: grade 0 - no discernible pelvic floor contraction, grade 1 - a flicker under finger, grade 2 - a weak contraction or increase in tension without any discernible lift or squeeze, grade 3 - a moderate contraction with partial lifting of postvaginal wall and squeezing of finger, contraction $>$ grade 3 is visible, grade 4 - good pelvic contraction causing elevation of post-vaginal wall against resistance and indrawing of perineum and, grade 5 - strong contraction of pelvic floor against strong resistance.

Levator muscles should also be palpated for tenderness or spasm.

Levator avulsion can be diagnosed by palpation during pelvic floor muscle contraction. Avulsion increases the levator-urethra gap, allowing it to admit not one but two fingers, and no contractile tissue is felt on the inferior pubic ramus (Figure 7).

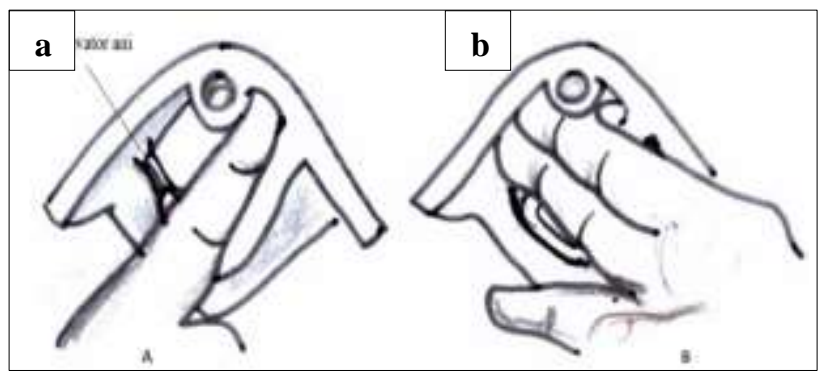

Figure 7: Diagram showing assessment of levator ani for trauma (a) palpation of normal LUG which admits one finger and, (b) a full avulsion with a LUG which admits two fingers easily.

\section{PERINEAL MEMBRANE}

Perineal membrane was previously called urogenital membrane. It lies inferior to the pelvic diaphragm below the urogenital hiatus of the levator ani muscle. It is a thick membranous triangular structure that spans the anterior half of the pelvic outlet and is attached to bony framework of pubic arch. The posterior triangle around the anus does not have a corresponding diaphragm or membrane. ${ }^{6}$

Perineal membrane has two openings in it, anterior one for urethra and posterior for vagina. Perineal membrane is attached on both sides to (Figure $8 \mathrm{a}$ and $\mathrm{b}$ ) aspect of inferior ischiopubic rami above the ischiocavernosus muscles and it's crura of the clitoris and the posterior border is free. Medially the perineal membrane attaches to the urethra, walls of the vagina, and perineal body. Due to presence of vagina, perineal membrane is not a continuous layer in women unlike men. ${ }^{6}$ Perineal membrane provides support to posterior vaginal wall by attaching vagina and perineal body to ischiopubic rami. ${ }^{6}$ Anteriorly there is a small gap between Inferior pubic ligament (ligament in pubic symphysis) and the membrane. ${ }^{23}$ Deep perineal pouch lies superior to the perineal membrane (Figure 9). ${ }^{10}$

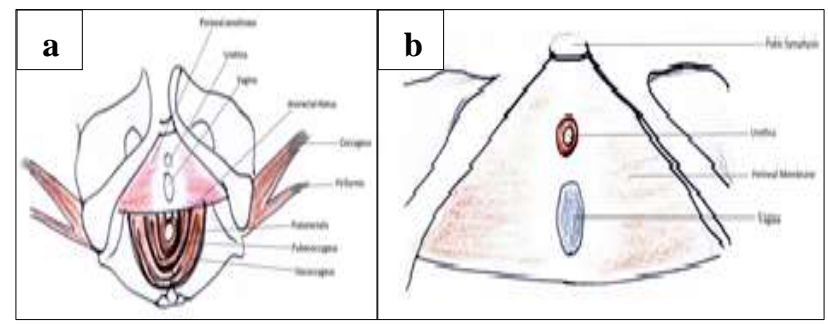

Figure 8: (a) and (b) Perineal membrane as seen from below.

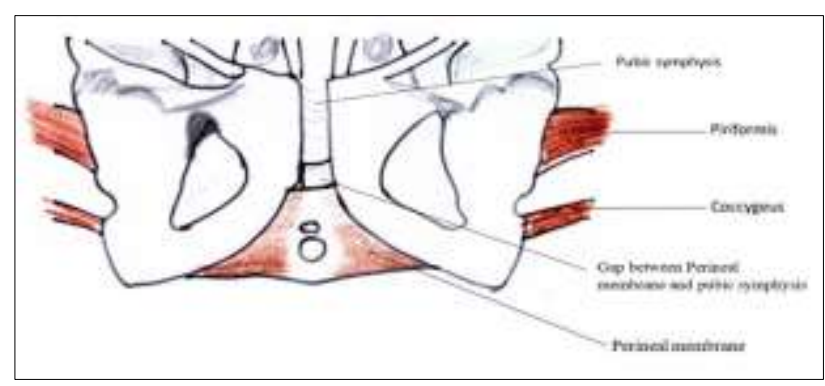

Figure 9: Perineal membrane, front view.

\section{Function of perineal membrane}

The pubococcygeal and puborectal portions of the levator ani muscles lie just at the upper margin of the perineal membrane and contact its cranial surface. Contraction of these muscles elevates the medial margin of the perineal membrane along with the vagina and relaxation allows for its caudal movement.

The primary function of the perineal membrane is related to its attachment to the distal vagina and perineal body. By 
attaching these structures to the bony pelvic outlet, the perineal membrane supports the pelvic floor against the effects of raised intra-abdominal pressure and gravity. ${ }^{6}$

The urogenital diaphragm closes the levator hiatus, has sphincter like effect on distal vagina and supports it. Perineal membrane also provides structural support for the distal urethra and contributes to urinary continence because it is attached to peri-urethral striated muscles.

\section{Assessment of perineal membrane}

We can assess downward descent of perineal body by connections of the perineal membrane to the midline structures during an examination under anesthesia. During EUA, place a finger in the rectum and hook it forward and gently pull the perineal body downward. If there is tear in the perineal membrane during parturition, then one can detect an abnormal amount of descent, sagging of pelvic floor and gaped introitus. ${ }^{6}$

\section{Perineal body}

Perineal body is also called central tendon of the perineum. It is ill defined connective tissue structure and lies at the midpoint of posterior border of perineal membrane. It is bound by lower vagina anteriorly, anus posteriorly and perineal skin on the undersurface. The perineal body is connected to ischial tuberosities and inferior pubic rami through perineal membrane. The lateral portion of upper surface of perineal body are attached to pelvic diaphragm. Posteriorly, perineal body attaches to coccyx through external anal sphincter which is attached to it. Perineal body connects the structures of perineum to pelvic cavity above. It gives attachment to the muscles of pelvic floor and the perineum. It receives attachment of superficial perineal muscles, bulbocavernosus muscles anteriorly. ${ }^{6,10}$

\section{Deep perineal pouch}

Deep perineal pouch is a fascial capsule above the perineal membrane and is open superiorly. It contains layers of skeletal muscles which include deep transverse perineal muscle, external urethral sphincter, compressor urethae and sphincter uretherovaginalis. These muscles differ in men and women. All these muscles are innervated by perineal branch of pudendal nerve. The muscles in the deep perineal pouch are described below (Figure 10 and 11).

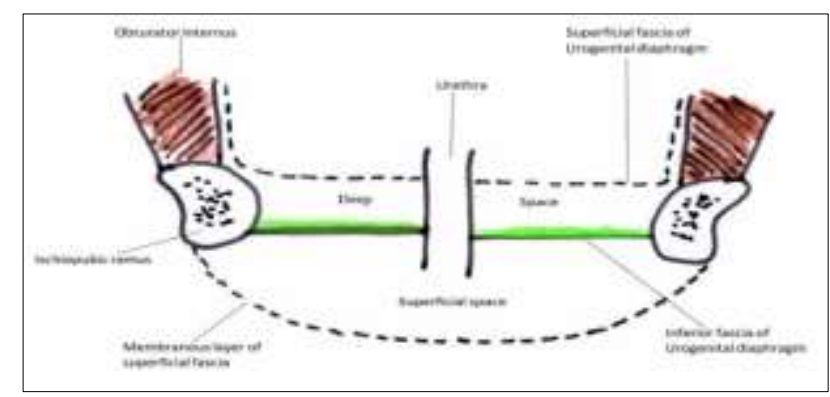

Figure 10: Cut section of deep perineal pouch.

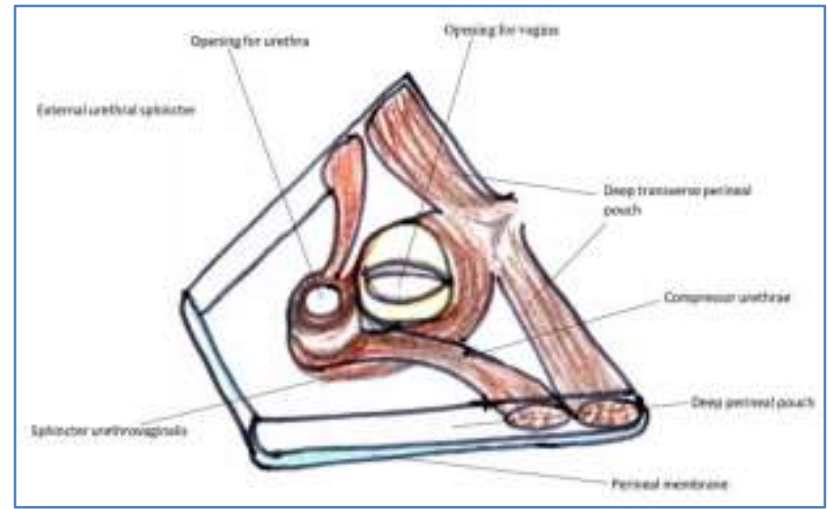

Figure 11: 3D section of deep perineal pouch.

\section{Deep transverse perineal muscle}

It is attached laterally to iscio-pubic ramus and inserts on perineal body.

\section{External urethral sphincter}

It surrounds the urethra.

\section{Compressor urethae}

It arises from ischio-pubic ramus, passes anterior to urethra to join the same muscle from opposite side. It aids the external urethral sphincter in closing the distal urethra. Posteriorly, it intermingles with skeletal muscle fibers of the transverse vaginal muscle and some smooth muscle fibers.

\section{Sphincter urethrovaginalis}

This muscle forms the sphincter around the opening of the vagina in the perineal membrane. The fibres are attached to perineal body, pass around vagina and then go anterior to urethra to merge with fibres of the opposite side. Anteriorly these fibres merge with compressor urethrae.

\section{Bulbourethral glands (Cowper's glands)}

They lie in the deep perineal pouch.

\section{CLINICAL SIGNIFICANCE OF PELVIC FLOOR}

\section{Pelvic organ prolapse}

If the connection of levator ani with endopelvic fascia breaks, then contraction of pelvic floor does not occur. When the pelvic floor muscles are relaxed or damaged, forces conferred by abdominal pressure are born by ligamentous and connective tissues. Although these ligaments can sustain these loads for short periods of time, but they stretch and eventually fail, resulting in pelvic organ prolapse. ${ }^{24}$

The attachment of levator ani to perineal body if damaged causes irreversible damage. 
Pelvic muscle exercise called Kiegel's exercise are effective in alleviating stress incontinence in many women. ${ }^{25}$ If a woman can control leakage by contracting her pelvic muscles before and during increased intraabdominal pressure, then Kiegel's exercise may be sufficient to treat stress urinary incontinence (Figure 10). The woman should remember to use this skill during activities that transiently increase abdominal pressure. ${ }^{26}$

Pelvic floor muscles can be damaged during child birth. During child birth, pubococcygeus undergoes maximum damage. Theoretically, the levator ani muscle may sustain either direct muscle or denervation injury during childbirth. During second-stage of labor, nerve injury from stretch or compression or both partially denervates the levator ani muscle. As muscle loses tone, the vagina drops from a horizontal to a semi-vertical position, the genital hiatus opens and pelvic viscera prolapse. If, there is partial tear of a portion of pelvic muscles which affect continence, then pelvic muscle exercises may be effective. Exercise cannot restore the portions of irretrievably lost muscles due to denervation. On the other hand, pelvic muscle exercises may cause agonist muscle hypertrophy, which may or may not restore continence depending upon how much the agonist muscles can compensate for the lost muscle function.

\section{Episiotomy}

The perineal body may be stretched and torn during vaginal delivery. Traditionally, obstetricians give episiotomy to prevent perineal tear. The episiotomy may be median or mediolateral. The median episiotomy passes through the perineal body and is in midline. On the other hand, the mediolateral episiotomy is at 450 from the midline. ${ }^{10}$

\section{CONCLUSION}

Change from quadruped to erect posture has resulted in changes in the human pelvis. This has resulted in the pelvis to support the abdominal viscera. The bony pelvis is deficient on inferior aspect. Pelvic floor is made of muscles covered by fascia on superior and inferior aspect. A good knowledge of pelvic floor is very basic and mandatory for any gynecologist as pelvic floor is crucial to support the pelvic organs and is required to maintain urinary and fecal continence.

Funding: No funding sources

Conflict of interest: None declared

Ethical approval: Not required

\section{REFERENCES}

1. Ashton-Miller JA, Delancy JOL. Functional Anatomy of the Female Pelvic Floor Ann. NY Acad Sci. 2007;1101:266-96.
2. Paramore RH. The uterus as a floating organ. In The Statics of the female pelvic viscera. 1918, ed 12. HK Lewis and Company. London.

3. Olsen AL, Smith VJ, Bergstrom JO, Colling JC, Clark AL. Epidemiology of surgically managed pelvic organ prolapse and urinary incontinence. Obstet Gynecol. 1997;89(4):501-6.

4. Abitbol MM. Evolution of the ischial spine and of the pelvic floor in the hominoidea. Am J Phys Anthropol. 1988;75:53-67.

5. Rosenberg K, Trevathan W. Birth, Obstetrics and human evolution. $\mathrm{Br} \mathrm{J}$ Obstet Gynaecol. 2002;109:1199-206.

6. Jones Howard W, Rock John A. Te Linde's Operative Gynecology. Wolter Kluwer. 11th ed. Lippincott Williams \& Wilkins (LWW). 2015.

7. Wilson D. Tail reduction in Macaca. In. Tuttle R (ed) The functional and evolutionary biology of primates. Aldine-Atherton, Chicago. 1972;249-61.

8. Ulfelder $H$. The mechanism of pelvic support in women: deductions from a study of the comparative anatomy and physiology of the structures involved. Am J Obstet Gynecol. 1956;72:856-64.

9. Wilson PM. Understanding the pelvic floor. SA Med J. 1973;47:1150-67.

10. Drake RL, Vogl AW, Mitchell A. Gray's anatomy for students. Elsevier. Third edition. Pelvis and perineum. 2015;216-9.

11. Moore KL, Dalley AF, Agur AMR. Clinically oriented anatomy, Wolters Kluwer/ Lippincott Williams \& Wilkins, 6th ed. Pelvis and perineum: 339-43.

12. Halban J, Tandler I. Anatomie und aetiologie der genital prolapse beim weibe. Wilhelm braumüller; wien: 1907.

13. Berglas B, Rubin IC. Study of the supportive structures of the uterus by levator myography. Surg Gynecol Obstet. 1953;97:677-92.

14. Marieb E. Human Anatomy and Physiology: books a la carte edition. Benjamin-cummings.6thed. Menlo Park, CA. 2004.

15. Taverner D. An electromyographic study of the normal function of the external anal sphincter and pelvic diaphragm. Dis Colon Rectum. 1959;2;153-60.

16. Smith ARB, Hosker GL, Warrell DW. The role of pudendal nerve damage in the aetiology of genuine stress incontinence in women. Brit J Obstet Gynaecol. 1989;96:29-32.

17. Enhorning, G. Simultaneous recording of intravesical and intra-urethral pressure. Acta Chir Scand. 1961;276:1-68.

18. Kim KJ, Ashton-Miller JA, Strohbehn K, DeLancey JO, Schultz AB. The vesico-urethral pressuregram analysis of urethral function under stress. J Biomech. 1997;30:19-25.

19. International Continence Society. Faecal incontinence - basics fact sheets. 2013.

20. Cundiff GW, Azziz R, Bristow RE. Te linde's atlas of Gynecologic Surgery. Wolters Kluwer, Lippincott Williams and Wilkins. 2013;217-9. 
21. Grigorescu BA, Lazarou G, Olson TR. Innervation of the levator ani muscles: description of the nerve branches to the pubococcygeus, iliococcygeus, and puborectalis muscles. Int Urogynecol J Pelvic Floor Dysfunct. 2008;19(1):107-16.

22. Chaitow L, Delany J. Clinical application of neuromuscular techniques. Churchill Livingstone. 2011;2.

23. Federative Committee on Anatomical Terminology (FCAT). Terminologia anatomica: International Anatomical Terminology. 1988.

24. B $\varnothing \mathrm{K}$, Talseth T. Long-term effect of pelvic floor muscle exercise 5 years after cessation of organized training. Obstet Gynecol. 1996;87:261-5.
25. Parks AG, Porter NH, Melzak J. Experimental study of the reflex mechanism controlling muscles of floor. Dis Colon Rectum. 1962;5:407-14.

26. Miller JM, Ashton-miller JA, Delancey JOL. A pelvic muscle precontraction can reduce cough-related urine loss in selected women with mild sui. J Am Geriatr. 1998;46:870-4.

Cite this article as: Mittal R, Rath G, Sahai RN, Aggarwal M. Understanding pelvic floor in women. Int J Reprod Contracept Obstet Gynecol 2020;9:432936. 